


\title{
Páginas devueltas: poemas desconocidos de José Revueltas
}

\section{Returned pages: unknown poems by José Revueltas}

\author{
Antonio Cajero Vázquez \\ El Colegio de San Luis, México \\ acajerov@hotmail.com
}

Resumen: José Revueltas fue un prolífico escritor del que, hasta la fecha, se han publicados 26 tomos como parte de sus Obras completas. No obstante, los estudiosos de su vida y obra se han dado a la tarea de rescatar muchos textos olvidados en archivos o publicaciones periódicas que Revueltas o sus editores descartaron de dicho proyecto. Para contribuir en tan loable labor de rescate, en este artículo, primero, reconstruyo sucintamente el nacimiento del poeta José Revueltas; luego, comento las ediciones de la poesía revueltiana y, finalmente, reproduzco seis poemas desconocidos por la crítica especializada.

Palabras clave: José Revueltas, poesía, El propósito ciego, rescate, poemas inéditos.

Abstract: José Revueltas was a prolific writer of which, to date, 26 volumes of his Obras completas have been published. However, the specialists of his life and work have been given the task of rescuing many forgotten texts in archives or periodicals that Revueltas or his editors discarded from that project. To contribute to such praiseworthy work of rescue, in this article, first, I succinctly reconstruct the birth of the poet Revueltas and, later, I comment on the editions of the revueltiana poetry and, finally, I reproduce six poems unknown by the specialized critic. 
Keywords: José Revueltas, poetry, El propósito ciego, Rescue, Unpublished poems.

Recibido: 3 de diciembre de 2018

Aceptado: 2 de abril de 2019

http://dx.doi.org/10.15174/rv.v0i24.448

Páginas devueltas: poemas desconocidos de José Revueltas

A últimas fechas, algunos estudiosos de José Revueltas han desAcubierto decenas de textos en prosa (crónicas, artículos periodísticos, ensayos y reportajes, columnas completas). En 2014, por ejemplo, Rosa María Ruiz Valles publicó José Revueltas, Letras rescatadas, una serie de reportajes aparecidos en la revista $A s i$, entre julio de 1943 y febrero de 1944. Por desgracia, la mayoría de ellos ya estaban compilados en Visión del paricutín. Más recientemente, en 2018, junto con Sergio Ugalde editamos La marea de los días, cerca de ochenta prosas de José Revueltas publicadas en la columna homónima del diario El Popular, entre agosto de 1941 y diciembre de 1942. Tengo conocimiento, también, de que hay quien está reuniendo las colaboraciones del duranguense en El Día.

Como parte de esta suerte de furor por el rescate de la obra invisible de Revueltas, en este artículo me propongo, primero, reconstruir el nacimiento del poeta; luego, analizar sucintamente las ediciones que se han hecho de la poesía revueltiana y, por último, reproducir seis poemas hasta ahora inéditos, todos ellos ubicados en el Archivo José Revueltas, en la Nettie Lee Benson Latin American Collection, Universidad de Texas, en Austin.

\section{Raíces del poeta José Revueltas}

De acuerdo con los paratextos de los escritos que rescato al final del artículo, José Revueltas escribió algunos de sus primeros intentos 
poéticos mientras se encontraba en Morelia, al parecer comisionado por el Partido Comunista, desde mediados de diciembre de 1936. Por los rastros en su correspondencia personal, puede constatarse que coleccionaba poemas para enviárselos a su entonces novia, Olivia Peralta, a quien bautizaría con el nombre de la heroína ibseniana de Peer Gynt: Solveig. Así, en carta del 15 de diciembre de 1936, el autor de El luto humano comenta a su corresponsal que le remitirá "la primera entrega de tu antología. Te preparo alguna cosa buena" (Revueltas, 1987a: 117). Ignoro si la antología mencionada estaría constituida por textos propios o ajenos porque, por ejemplo, en el manuscrito de "Canto irrevocable" (mayo de 1938), de su autoría, se puede leer: "Antología por entregas para Solveig”. Para aquellas fechas, lo más seguro es que se tratara de textos de autores que influyeron y modelaron su juvenil producción poética. Como Huerta, aunque con menos prolijidad, Revueltas se habría vuelto poeta al amparo de los efluvios amorosos de su correspondencia, tal como lo ha demostrado Isabelle Pouzet en el caso del guanajuatense (2013).

Esta inclinación por expresarse poéticamente aparece de nuevo manifiesta el 23 de mayo de 1938, cuando Revueltas escribe a su "Adorada Solveig": "Te adjunto un poema que hice, está muy mediano. Puede que me arriesgue a publicarlo aquí" (1987a: 146). Por descuido, o más bien por un acto fallido, el remitente olvida adjuntar el poema prometido y sólo cumple su cometido en la misiva del día siguiente, donde refuerza su opinión sobre la calidad del texto: "En la carta de ayer te decía que adjuntaba un poema. Sí, debería haberlo adjuntado pero se me olvidó. Creo que en ésta no se me olvidará. Está muy mediano; pero en fin" (Revueltas, 1987a: 147). Debido a que "Canto irrevocable" y "[Si el aire...]" están fechados en "Mérida, Yuc. // Mayo 1938" resulta imposible saber a cuál de estos dos poemas se refería Revueltas: me inclino, sin embargo, a suponer que se trataba del primero, ya que tiene una 
factura más elaborada, como lo confirma el original de la plaquette conservado en Austin.

Durante su estancia en Mérida, por cierto, Revueltas mantiene correspondencia con Efraín Huerta, César Chamaco Ortiz y Luis Mondragón, camaradas del Partido Comunista. Aun cuando hay testimonios epistolares de los tres, en este caso únicamente quisiera reproducir las líneas donde Ortiz le restriega a Revueltas sus veleidades líricas:

Hoy como la otra vez -cuando te hice mi anterior- he tenido la mala pata de encontrarme con tu compañera en casa del Doctor y realmente me ha conmovido tanto que las dos veces he llegado a una máquina para escribirte y en esa forma saciar mi desesperación.

No me resisto las ganas para comentar las otras "cosas" que tu mujer me enseñó, tú bien sabes que se trata de los recortes de periódicos que no dejando de ser tal lo verdaderamente inexplicable es que todos son dedicados como poemas a lo que tu llamas "tu mujercita” Qué descaro!!!!!!! Pero el crimen está en que tú hablas, dices y escribes lo que otros hablan, dicen y escriben. Hasta cuándo, señor dios, dejarás de tu mano a este pobrecito niño????? Hasta cuándo señor Rev. dejará Ud. de plagiar a los grandes cerebros de la humanidad? Hasta llega Ud. a meterse con los vivos y desaparecidos. Cuántas ignominias tiene que soportar el público pueblerino de los periódicos y cuántas desgracias le deparan a México con tipos como Ud.

La verdad es que sólo vi unas cuantas líneas y fue eso lo que encontré. Seguramente oíste a Cárdenas en una cervecería o seguramente ya eres otro. ${ }^{1}$

${ }^{1}$ Carta de César Ortiz a José Revueltas, 15 de junio de 1938, José Revueltas Papers, Nettie Lee Benson Latin American Collection, Universidad de Texas, Austin. La carta previa a la que se refiere Ortiz está fechada el 8 de junio y en ella también alude al encuentro con Olivia Peralta en el consultorio del doctor Herrada, quien supervisaba el embarazo de la mujer de Revueltas: "Hoy me 
Hasta donde conozco, Revueltas no publica un solo poema en el Diario del Sureste; por ello, supongo que las otras cosas a que alude Ortiz son los artículos que entregaba regularmente al periódico yucateco. Por ejemplo, Revueltas había publicado el 8 de junio una nota sobre Puente en la selva, de Traven, que el mismo día adjunta en la consuetudinaria carta a Olivia, además de ofrecerle un poema de Neruda para otra ocasión: "Antier estuve tan nostálgico, que hasta cerca de la medianoche estuve cantando en la terraza de la casa donde duermo. Pensando mucho, atrozmente en ti. Tengo el libro de Neruda, Veinte poemas de amor y una canción desesperada. Mañana o pasado te envío un poema" (Revueltas, 1987a: 152). ¿En qué se basaba Ortiz para acusar a Revueltas de descarado y plagiario? En haber visto "unas cuantas líneas y eso fue lo que encontré".

No hay que tomar tan en serio el comentario, sin embargo, porque el humor negro afloraba con frecuencia entre Revueltas y sus correligionarios. Como se observa, el hábito adquirido en diciembre de 1936 de antologar textos para Olivia resulta lo más natural en las cartas de Revueltas, igual que las recomendaciones de lecturas o las citas de autores que refuerzan sus argumentos, como en la carta del 20 de junio, que empieza con una afirmación contundente: "Hoy, no sé por qué, me siento lleno de poesía y bondad a pesar de mis frecuentes oscuridades". Luego reproduce la segunda cuarteta de la elegía "Xxiv" de Juan Ramón Jiménez. Líneas adelante, Revueltas señala: "Terminaré con un poema de Juan Ramón y otro que quiero le des a conocer a Silvestre, de Pablo Neruda". Según los editores de Las evocaciones requeridas, los

interesé más en escribirte porque en la casa del doctor me encontré con tu compañera y me dijo que te encuentras disgustado con nosotros por la falta de nuestras palabras santas". Sobre el tema también puede consultarse Revueltas (1987a: 137-177). 
poemas antologados eran "Adolescencia” de Juan Ramón y "dos poemas sin título de Pablo Neruda": al consultar el original de la carta, se puede constatar que se trata de los poemas " $\mathrm{x}$ " $\mathrm{y}$ " $\mathrm{xx}$ " de Veinte poemas de amor y una canción desesperada, por lo que puede afirmarse que no fueron dos, entonces, los poemas antologados, sino tres (Revueltas, 1987a: 158 y 328). Hasta aquí el recuento de cómo surge el poeta y sus prácticas escriturarias en relación con la poesía hacia finales de los años treintas del siglo pasado, cuando escribe los poemas anexos a este artículo.

\section{El poeta y sus editores}

Esta faceta de Revueltas como poeta no siempre se mantuvo al margen de su producción; por el contrario, fue objeto de crítica, como lo acredita el texto que Efraín Huerta le dedica en su columna "El Hombre de la Esquina". De esta manera, además de ser el autor del primer juicio público sobre El quebranto (Huerta, 1938: 3), Huerta deviene descubridor de un talento lírico cuya autenticidad y sencillez contrasta con la impostación de "los oficiales y aprendices de la poesía”:

Lo que a los poetas, mejor dicho, lo que a los oficiales y aprendices de la poesía, les es negado un día y otro; es decir, la expresión natural, espontánea, abierta, plena y sencilla, a ciertos hombres no se les oculta. De una voz, de una potencia lírica, puede salir un magnífico fruto de sinceridad y de amor. De sinceridad y amor a todas las cosas y a todos los sentimientos. Y por todos los sentimientos. Por lo que el mundo enseña y niega, por lo que la vida deshizo, por todo eso que la juventud prodiga.

Sorprender al autor de Los muros de agua escribiendo versos, no es noticia. Es confirmación de los antiguos cantos apasionados. Confirmación y afirmación de aquellas dos voces desaparecidas: la de Fermín y la de Silvestre. Esta voz de José, tan tímida -y tan 
violenta-, tan lenta y entrecortada, es una herencia y una conquista. Quiero decir que el escritor, como su poesía, está en todas partes. Cuando, de regreso de Moscú, descendió en Santander, no a pescar, sino a comprar un libro de Federico García Lorca, no hacía otra cosa que revelarse. Y sembrar. Este poema lo dice (Huerta, 1942: 5).

Para confirmar sus aseveraciones, El Hombre de la Esquina copia íntegramente el poema "La cosecha", única versión conocida del poema que sirvió de base a la recogida en 1981, cuando Andrea Revueltas y Philippe Cheron reunieron 31 poemas en el tomo 11 de las Obras completas, Las cenizas (Obra literaria póstuma), de José Revueltas. Las fuentes del "Tercer apartado. Poemas", sin embargo, no se reducen a los diarios y revistas donde Revueltas publicó alguna muestra lírica (El Popular u Hojas de Literatura), sino que también se consultaron manuscritos y mecanuscritos. Esta muestra abarca de 1934 a 1974, cuarenta años en que Revueltas ensayó un lirismo de contrastes: entre el amor y el dolor, entre lo personal y lo colectivo, entre la razón y la afrenta, entre el temor y el temblor bíblico que cruza toda su obra: una existencia, en fin, puesta al servicio de las causas sociales desde su más temprana juventud. Así lo corrobora el testimonio poético más remoto de Revueltas, ya que "Nuestra manzana del padre Adán", con su inevitable alusión al pecado, fue escrito y firmado en "Islas Marías, octubre de 1934".

En 2001, después del trabajo de Andrea Revueltas y Philippe Cheron, con el título de El propósito ciego, José Manuel Mateo publicó los 31 poemas de Las cenizas, más otros dos: "El tiempo y el número" y "Safo y Adonis" (Mateo, 1991; Mateo, 2014). Del primer poema puede decirse que únicamente lo reacomodó, porque ya había sido publicado en Las cenizas con el título de "Para El tiempo y el número (Esquema para una prosa)", como preámbulo de los fragmentos de la novela El tiempo y el número. Del segundo poema, Mateo comenta que, mientras se encontraba en el trabajo 
de cotejo de los originales para la edición de El propósito ciego, Andrea Revueltas encontró "Safo y Adonis", mecanografiado y firmado por Revueltas. Hasta la fecha, el corpus lírico de Revueltas se había constreñido a los 33 poemas coleccionados y anotados por José Manuel Mateo.

\section{Los poemas desconocidos}

Ahora bien, en el Archivo José Revueltas, alojado en la Nettie Lee Benson Latin American Collection, se encuentran otros poemas no reunidos por sus editores. Sospecho que no serán los únicos que han quedado fuera de las Obras completas: seguramente existen algunos más entremezclados entre borradores, fotocopias, cuadernos e innumerables papeles ajados por el tiempo. ${ }^{2}$ He aquí la lista de los hallazgos que he venido anunciando:

1. "Pittsburgh (El Barrio Negro)", mecanuscrito fechado "Agosto de 1936 ".

2. "A Solveig", manuscrito fechado "Nov[iembre] 17 de 1936", cuya versión mecanuscrita presenta algunas variantes, así como la eliminación de la preposición en el título: "Solveig" y con la fecha menos precisa, "Noviembre de 1936".

3. Sin título, con el incipit "TAN concreta, tan concreta...", mecanuscrito fechado en "Diciembre de 1936".

4. "Digo que te amo // para Solveig, mi compañera", manuscrito fechado en "Mayo de 1937".

5. Sin título, con el incipit "ESCALA verde..." fechado en "Uruapan Mic. Sept. de 1937".

\footnotetext{
2 Por supuesto, cuando se complete la poesía de Revueltas, también tiene que incluirse en el corpus el poema dedicado a Omega (Revueltas, 1987b: 128-129). No lo incluyo aquí, porque no se trata de un texto desconocido, sino olvidado entre las obras publicadas, como habría ocurrido con "Para El tiempo y el número (Esquema para una prosa)", rescatado por Mateo en 1991.
} 
6. Sin título, con el incipit "SI los fusiles los fusiles los fusiles...", sin lugar ni fecha.

De estos seis poemas, el que presenta una historia anómala es "Digo que te amo", porque de él se conserva una versión manuscrita, así como una mecanuscrita donde la dedicatoria cambia "A Olivia" y la fecha se elimina; además, habría que preguntarse por qué "Digo que te amo" no fue recogido por los editores de la poesía revueltiana, si se publicó junto con "Canto irrevocable" y "La última voz" (Cf. "Tres poemas", Esfera Siete, invierno de 19771978, p. 3; dibujos de Alfonso Lara Gallardo). Estos últimos, por el contrario, sí fueron coleccionados tanto por Andrea Revuelas y Philippe Cheron como por José Manuel Mateo.

Sobre los motivos de la exclusión, olvido u omisión de los poemas aquí rescatados podrían establecerse dos líneas conjeturales: 1) a mi juicio, tanto "Digo que te amo" como "A Solveig" fueron descartados porque en ambos casos la dedicatoria estaba explícitamente referida desde los paratextos: Solveig, Olivia Peralta, la primera esposa de Revueltas. ¿Se trató de una censura contra el pasado? Más aún: quizás el tono amoroso, incluso sensiblero, de este par de poemas rompía con la unidad de El propósito ciego, cuyo carácter (auto)crítico, y hasta críptico, domina el conjunto; 2) "Pittsburgh (El Barrio Negro)" y los tres restantes poemas sin título revelan una poética juguetona, entre paródica y ancilar, inspirada acaso por Nicolás Guillén y Pablo Neruda. Aun cuando pueden apreciarse limitados y reiterados artificios retóricos en todos ellos, considero que revelan una búsqueda de la musicalidad y el ritmo por medio de las repeticiones, los estribillos y las asonancias, infrecuentes en los poemas de El propósito ciego. Considero, también, que la abundancia de ripios implícitos en las estructuras ecoicas en todos los planos (fonético, léxico, sintáctico) tiene la misma intención de acercar el poema a la música, al juego infantil a veces, como en "Pittsburgh" (¿Se aprecia el halo de "La muralla", de 
Guillén?). Más que un análisis exhaustivo, quisiera traer a colación algunos ejemplos de los recursos retóricos que he mencionado:

a) En varios poemas, es posible apreciar tiradas completas donde rigen las repeticiones y las rimas consonantes, cacofonías casi, con un consecuente efecto sonoro coincidente con el sentido amplificatorio de algunas tiradas:

TAN bajo el cielo, tan bajo, que bajo el mundo, tan bajo, se quiebra el cielo, se quiebra, y el cielo enhebra, lo enhebra. ("Pittsburgh")

En tu alto mar en tu alto mar en tu alto mar me meciera ("A Solveig")

b) Asimismo, ciertas estructuras anafóricas permiten imaginar la intensidad de tono, por un lado, y una abrumadora acumulación que desafía al lector con series de imágenes en tropel, por otro. Estas construcciones anafóricas, combinadas con paralelismos sintácticos, vuelven previsible el recurso, y lo empobrecen; aunque también abren una variedad de posibilidades de sentido y relaciones semánticas económicas desde el punto de vista de la retórica. Cito algunos ejemplos:como claveles de azafrán,

como claveles de azafrán,

como sin límites

como sin alturas

como sin aguas.

Lo que a la pesadilla. 
Lo que a lo negro.

(“TAN concreta, tan concreta...")

y la carne roja

y la carne blanca

y la carne grave

y la carne tierna

y la carne breve

y la carne buena

(“SI los fusiles los fusiles los fusiles...”)

Como señalé, más que ser exhaustivo en el análisis de esta primicias, quise hacer énfasis en los principales recursos retóricos de un poeta en ciernes que apostó por ser un narrador con esporádicas incursiones líricas. Con el tiempo, sin embargo, habrá de adquirir una profundidad apenas perceptible en los textos que permanecieron archivados (¡censurados?) durante años. La poesía revueltiana saltó como un tema novedoso desde 2013 con la ponencia "La sangre derramada: la poesía reflexiva de José Revueltas”, de Elba Sánchez Rolón en Xalapa, Veracruz; luego, Eduardo Martín del Campo hizo una inteligente lectura del motivo del tiempo y el espacio en El propósito ciego (2014), y, finalmente, Andrés Avilés Hirales proporcionó una reflexión más amplia y profunda al respecto con su tesis de maestría, La imagen poética en "El propósito ciego" de José Revueltas (2018), la cual representa un valioso y riguroso estudio sobre la poesía revueltiana, y un desafío para quienes deseen acercarse al tema.

Para cerrar sólo quisiera agregar que, además de su inestimable valor testimonial, en los poemas rescatados puede verse la vena experimental del joven Revueltas en busca de una voz. Después de los ejemplos que he mencionado, sospecho que la crítica en torno de la poesía revueltiana habrá de incrementarse. No puede seguirse sosteniendo que en torno de ella existe una tierra baldía, como lo sugería Martín del Campo en el incipit de su ensayo: "Después de treinta y tres años de su publicación en las Obras completas (1981), todo el corpus lírico existente (treinta y un poemas, publicados 
e inéditos) de José Revueltas parece no haber despertado mayor atención ni inquietud crítica, al contrario del resto de su obra (narrativa y crítica)" (2014: 61). Con los rescatados por José Manuel Mateo ya eran 33 poemas en 2014. Ahora bien, con los que enseguida reproduzco y el dedicado a Omega serían 40. Los acercamientos críticos, por su parte, han alcanzado el calibre de una tesis de maestría. Finalmente, he aquí los poemas desconocidos para que el lector ejercite su criterio y complete la imagen del poeta de clóset que fue José Revueltas.

\section{Pittsburgh \\ (El Barrio Negro)}

TAN bajo el cielo, tan bajo, que bajo el mundo, tan bajo, se quiebra el cielo, se quiebra, y el cielo enhebra, lo enhebra.

Lo enhebra en cables negros $\mathrm{y}$ voces obscuras; en criminales chimeneas apuntaladas a triste toldo de circo; en rojos ladrillos destilando agua negra; en negritos que juegan muy negros, botados de las chimeneas al estanque.

Altas las manos para mancharse en las nubes de pardo las manos. 


\begin{abstract}
Alto el cuerpo para
mancharse el cuerpo

de pardo en los cables.

Para los negritos que juegan

para los negritos que lloran

para los negritos ciegos

para los negritos.
\end{abstract}

Agosto de 1936
A Solveig
Alba del alma
blanda alba blanca
mía alma
como el aire ${ }^{3}$
rodando como el aire
más viento
que el malva viento.

\begin{abstract}
En tu alto mar
en tu alto mar

en tu alto mar

me meciera
\end{abstract}

de niño de nube
de lino
de nido
de luna
en tu alto mar $^{4}$

${ }^{3}$ Verso eliminado en el mecanuscrito.

${ }^{4}$ En el mecanuscrito, esta estrofa sigue un orden distinto: "de niño / de lino / de nido / de nube / de luna / en tu alto mar". 
Me meciera

me meciera

en tu mar.

Nov[iembre] 17 de 1936

TAN concreta, tan concreta

que eres al tacto

lo que el viento a las venas

a las sienes.

Lo que la luna

a la mancha.

Lo que la noche verde

químicamente descompuesta

en un vaso de agua

al silencio

o a la frente

o al reloj.

Concreta.

Estatua traducida

a minutos vencidos con los dedos, derrotados con un bisturí en silencio.

Presencia dentro del vaso,

dentro de la angustia,

en la noche sin pulmones.

Ángel de cara negra, con rosas,

químicamente puro

como claveles de azafrán,

como sin límites

como sin alturas

como sin agua. 
Lo que a la anemia

una mañana amarilla

de tus voces.

Concreta. Sí.

Sí.

Lo que a la pesadilla.

Lo que a lo negro.

Diciembre de 1936.

\section{DIGO QUE TE AMO}

para Solveig, mi compañera.

CON un amor que no alcanzan las negaciones inauditas de las maneras

ni las impotentes paredes estranguladas del segundo

ni las vértebras ni lo inorgánico mismo

que no alcanzan los cauces

ni los cauces de los cauces

Con un amor claramente fijo en el espacio

limpiamente desnudo en la luna

acuáticamente puro

Digo que te amo

-oh rumor sin espanto

y discurrir líquido del viento-

abiertos los canales del sueño

sin párpados la alegoría castaña de tus ojos.

Mayo de 1937. 
ESCALA verde

para los ángeles jóvenes

escala verde hacia el cielo.

¡Cómo brilla el aguacate, cómo brilla, amor mío, con su corona de nubes!

Malva risa tibia

de las hojas del plátano sobre los cafetos, escala verde.

Atabales en lo más alto del agua sobre batientes de rosas.

Toqui-toqui-toqui ${ }^{5}$

Y el señor de las yedras en los mameyes a lo alto.

Toqui-toqui-toqui

¡cómo brilla amor mío!

Bajo el platanar el cafeto, bajo el cafeto mi amor, ay! desnuda en el agua, en el agua quebrada mi amor.

Tiquití-toqui

Toqui-tiquití.

${ }^{5}$ Ritmo que se usaba en los cantos mexicanos (nota original de José Revueltas). 
Suave lengua tarasca

el río viene lleno de agujas

con sus salivas calientes

El río claro

con sus espejos quebrados.

Tiquití-toqui

Toqui-tiquití.

Uruapan, Michoacán; septiembre de 1937.

SI los fusiles los fusiles los fusiles

perforaron las montañas

y una estrella una estrella una estrella

la dejaron en la punta

y la bañaron de mañana.

PIES desnudos en Perm

uñas heladas en Tzaritzin

dientes en Perm

cabellos locos en Tzaritzin

y soldados

y soldados

con el pecho abierto

y la carne roja

y la carne blanca

y la carne grave

y la carne tierna

y la carne breve

y la carne buena

lenta

en las púas

de los [alambres] 
en Tzaritzin

en Perm.

Si los fusiles si los fusiles los fusiles en Odesa

Si los fusiles si los fusiles los fusiles

allá

dejaron estrellas

y tractores

y muchachas

y puños alegres

lavados de mañana

o kirguises

o usbeks

o kalmukos

o kilómetros

o dinamos

que gritan

gritan

gritan

sienten

\section{Bibliografía}

Avilés Hirales, Andrés, 2018, La imagen poética en "El propósito ciego", tesis de Maestría en Literatura Hispanoamericana, El Colegio de San Luis, México.

Huerta, Efraín, 1938, "El mundo del quebranto", El Nacional, México, 16 de mayo, p. 3.

1942, "El Hombre de la Esquina. José Revueltas”, El Popular, México, 13 de mayo, p. 5. 
Martín del Campo, Eduardo, 2014, "La dialéctica de la noche, la dialéctica inversa”, Tierra Adentro, núm. 197, noviembre, pp. 61-63.

Pouzet, Isabelle, 2013, De la lettre au poème: de la correspondance d'Efraín Huerta (1933-1935) à la genèse de'une auvre, 2 ts., tesis de Doctorado, Université Rennes 2, Rennes, Francia.

Revueltas, José, 1987a, La evocaciones requeridas, t. 1, ed. de Andrea Revueltas y Philippe Cheron, México, Era.

, 1987b, La evocaciones requeridas, t. 2, ed. de Andrea Revueltas y Philippe Cheron, México, Era.

, 1991, El propósito ciego, ed. de José Manuel Mateo, México, Aldvs/Obra Negra.

, 2014, El propósito ciego, ed. de José Manuel Mateo, MéxiCO, Era/FCE.

, 2015, Letras rescatadas, comp. de Rosa María Valles Ruiz, Pachuca, UAEH.

, 2018, La marea de los días, ed. de Antonio Cajero y Sergio Ugalde, México, FFyL-UnAM.

Sánchez Rolón, Elba, 2013, "La sangre derramada: la poesía reflexiva de José Revueltas”, ponencia léida en el Tercer Congreso Internacional de Investigaciones Literarias, Xalapa, Ver., 18-21 de junio.

\section{Archivo}

José Revueltas Papers, Nettie Lee Benson Latin American Collection, Universidad de Texas, Austin. 